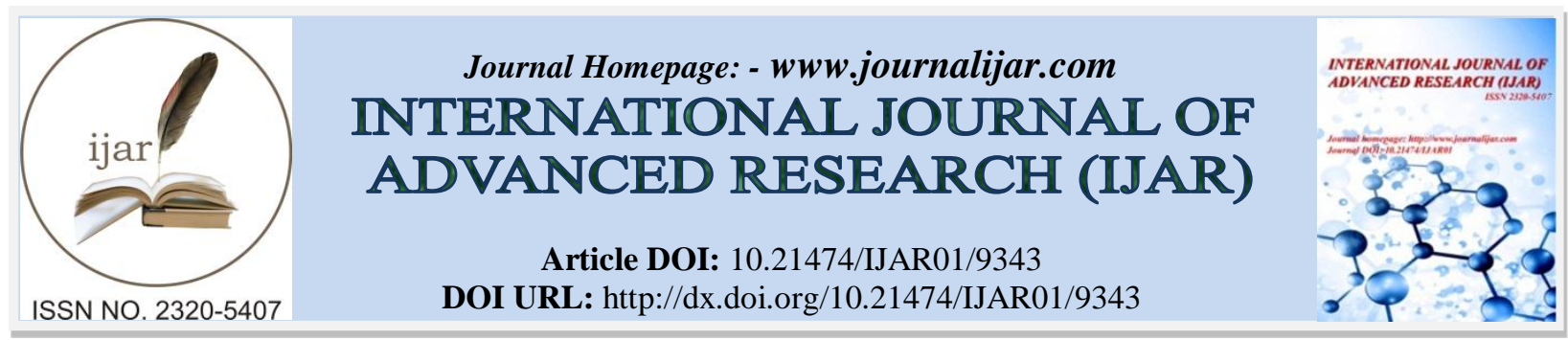

RESEARCH ARTICLE

\title{
EFFECT OF SOCIAL CAPITAL DIMENSIONS ON THE APPLICATION OF PATIENT SAFETY BY NURSES PRACTITIONER AT MOROWALI GENERAL HOSPITAL, INDONESIA 2019.
}

"Eka Nurul Fadhilah ${ }^{1}$, Syahrir A. Pasinringi ${ }^{2}$ and Atjo Wahyu ${ }^{3}$.

1. Master of Hospital Administration Management, Hasanuddin University, Indonesia .

2. Departement of Hospital Administration Management,Public Health Faculty, Hasanuddin University, Indonesia.

3. Departement of Occupational Safety and Health, Public Health Faculty, Hasanuddin University, Indonesia.

\section{Manuscript Info}

Manuscript History

Received: 04 May 2019

Final Accepted: 06 June 2019

Published: July 2019

\begin{abstract}
Patient safety there is a system created by the hospital so that patient care is safer, preventing injury due to errors and carrying out actions or not carrying out the actions that should be taken. Social capital can be interpreted as institutions, relationships, attitudes and values that facilitate interaction between individuals between community groups, The purpose of this study was to determine the effect of social capital dimension on application of patient safety at Morowali General Hospital. This research was conducted at Morowali General Hospital, Central Sulawesi, Indonesia. The type of research used is quantitative using observational analytic design with cross sectional approach. The sample of this study was 150 respondents who were nurses from all units in the hospital. In this study using a questionnaire and data were tested using Pearson correlation test. The results of this study indicate that the correlation between interaction and shared vision towards application of patient safety obtained a value of $\mathrm{p}<0.05$ which means that there is influence between communication and shared vision amongs nurse relation to patient safety.
\end{abstract}

Copy Right, IJAR, 2019,. All rights reserved.

\section{Introduction:-}

The focus on patient safety is growing along with the increasing number of incidents of patient safety globally and nationally. Patient safety incidents in Health Ministry Regulations No. 11 of 2017 is unintentional event and condition that results or potentially results in an injury that can be prevented in the patient.

The incidence of patient safety and hospital performance is caused by several factors, namely the factors of hospital standards facilities, leadership factors, labor factors, and workload factors (Griffiths, Renz, Hughes, \& Rafferty, 2009), according to (Nursalam, 2011) the factors related to the incidence of patient safety are individual nurse performance in providing nursing care.

In the program to the salvation of patients in hospitals, the role of nurses as health workers is the most dominant providing services, recorded in Indonesia 33.3\% of the total health workers, amounting to 3,406,558 people (Kemenkes RI, 2017). Focusing on the role of nurses in providing services is at the forefront of preventing or 
minimizing medical errors by responding immediately and taking corrective actions (Despins, Scott-Cawiezell, \& Rouder, 2010).

The concept of social capita is currently developing and has become an important issue in society. Now there is impressive empirical evidence about social capital as a determinant in the health sector (Poortinga, 2006). It can be said that the development of this concept is based on the understanding that social capital will affect performance.

In hospitals it is important for the involvement of health workers in improving patient safety, it requires good teamwork and a good care environment (Manser, 2009). Social capital in hospitals can be seen as a resource for organizations in a sustainable system, especially in improving patient safety.

Causes of medical errors can include communication problems, inadequate flow of information, problems involving human factors, issues relating to patient factors, transfer of knowledge in the organization, work patterns and workloads, technical failures and policies and procedures (Fleming \& Wentzell, 2008).

According to (Reason, 1995) nurses who are the final health care providers interact with patients, are the last limit of preventing incidents of patient safety, hence being the most vulnerable.

Social capital (interaction, trust, shared vision) can generate ownership in the community that can help nurses find strength by getting to know others who are in the same situation, which in turn can foster mutual support and influence nurse satisfaction and retention (Looman, 2006; MacPhee \& Scott, 2002)

This is an important concept for health systems throughout the world, because the provision of clinical care is shifting towards a model of teamwork, collaboration and health system reform. Adapted Social Capital in SCQI can produce valuable findings for policy makers and contribute to building a cohesive integrated health care team that can achieve the desired results to produce more quality health care for patients (Sheingold, Hofmeyer, \& Woolcock, 2012).

Patient safety programs are considered as a factor that directly affects the incidence of patient safety. Patient safety has become one of the main priorities of health services and is sought extensively from the global level to the micro system (WHO, 2009). The Institute of Medicine suggested that to reduce the incidence of patient safety it is necessary to improve patient safety programs, the program will make it difficult for health workers to make mistakes and prioritize doing the right things (Kohn, Corrigan, \& Donaldson, 1999).

At the hospital, the problems of health such as incomplete or unwritten reports, validation problems and adverse events that were found not followed up and there was no effective learning feedback or corrective action implemented to prevent recurring similar incidents (Dhamanti, Leggat, \& Barraclough, 2019).

Based on an explanation of the importance of hospital patient safety being able to provide quality health services, this study focuses on how the effect of social capital dimention on implementation of a system for improving patient safety at Morowali General Hospital Indonesia.

\section{Social Capital}

Social capital is defined as a collective relationship that can provide useful resources for individual interests in the present or in the future (Green \& Petre, 1996). Based on a comprehensive review of previous research on social capital, Nahapiet and Ghoshal (1998) classify social capital into three dimensions: structural dimensions, cognitive dimensions, and relational dimensions.

Structural dimension

The structural dimension identifies areas where the social interactions of people in the organization are connected together (Bolino, Turnley, \& Bloodgood, 2002)

Relational dimension

The relational dimension represents the type of personal relationship that focuses on the trust of one of the most studied and critical factors that influence honest, orderly behavior, and collaboration based on shared norms (Fukuyama, 1995; R. D. Putnam, 2002). Actually this dimension considers effective relationships between 
coworkers, trusting one another, and uniting identities (Chang, Huang, Chiang, Hsu, \& Chang, 2012). Therefore, trust is considered a key feature in social communication and exchange (Doh \& Zolnik, 2011)

Cognitive dimension

The cognitive dimension involves resources that provide meaning and mutual understanding in the organization. In the initial research, Nahapiet and Ghoshal (1998) linked the cognitive dimension with shared language and sharing narratives, but other authors then described it as a shared vision and shared culture (Tsai \& Ghoshal, 1998).

Relationship between social capital and patient safety

Patient safety can be categorized into four components in the organization: practice, workforce work, work design and organizational culture (Institute of Medicine, 2004). Several studies have shown that good employment relationships in the nursing environment are very important for nurses and patients (Aiken et al., 2011; Spence Laschinger \& Leiter, 2006). Their research shows that hospitals as health care providers should strive to develop a culture that emphasizes team work which is an important factor to ensure efficiency and quality of care (Meterko, Mohr, \& Young, 2004). So organizational culture is a source for improving patient safety practices and important support to prevent and avoid medical errors (Sammer, Lykens, Singh, Mains, \& Lackan, 2010). Firth-Cozens, (2004) states that social capital in hospitals is an important factor for making the system safe. According to the characteristics of social capital that have been mentioned, that not only individuals, but also complex organizations, such as hospitals have been influenced by the concept of social capital. It is assumed that social capital in hospitals can be a key factor in making a patient safe environment (Jafari, Pourtaleb, \& Khodayari-Zarnaq, 2018)

\section{Materials And Method:-}

\section{Location and Research Design}

This research was conducted at Morowali General Hospital, Central Sulawesi, Indonesia. The research type used is quantitative by using analytic observational design with cross sectional approach.

\section{Population and sample}

The population in this study were all nurses at Morowali General Hospital. The sampling technique used is exhaustive sampling which is all sample are population into the study many as 150 nurses who fulfill the inclusion criteria.

\section{Method of Collecting Data}

In this research uses data collection method with questionnaires by distributing questionnaires to respondents and then the respondents fill the questions contained in that questionnaire. First, the questionnaire has been tested for validity using a correlation technique with the Pearson correlation value $>\mathrm{r}$ table $(0.3061)$ and reliability with the value of Cronbach's Alpha > 0.6 with a total sample of 30 people. Validity test results it was found that of the 50 statements for revealed about the dimensions of social capital (structural,relational,shared vision) and the application of patient safety by nurses declared valid and reliable, so that it can be used in research.

\section{Instruments}

The questionnaire items used measured nurses' perceptions on a Likert 6-point scale. The survey questionnaire consists of two parts. The first part is related to measuring the dimensions of social capital following Nahapiet and Ghoshal (1998) using three dimensions of social capital (structural, relational and cognitive). Structural dimensions measured by 5 items about social interaction between nurses, relational dimensions based on trust perception 5 items were used to measure nurse beliefs and cognitive dimensions containing statements about shared vision measured 5 items developed using a modified questionnaire from the study Chang et al., (2012) and modification of Leana \& Pil, (2006). The second part of the questionnaire measures patient safety according to patient safety goals. The target of patient safety is in accordance with the regulations of the Minister of Health No. 11 of 2017 in accordance with the International patient safety goals (IPSG). Nurses were asked to report on the extent of their achievements in implementing patient safety at the hospital.

\section{Data Analysis}

The analysis techniques used univariate analysis and bivariate analysis. Univariate analysis is used to describe variables by calculating frequency distributions. Meanwhile bivariate analysis is used to know the relationship of each independent and dependent variable, which is by using Pearson correlation test. 


\section{Results:-}

Table 1 shows that frequency distribution of respondents at Morowali General Hospital in 2019 based on the highest age characteristics in the 30-39 year age group (51.3\%), while the respondent's gender in this study was dominated by women is 115 respondents (75.7\%) and male gender is 35 respondents $(23.3 \%)$. The highest level of last education of the respondents came from nursing D3 education, which was 117 respondents ( $78 \%$ ). There are 122 respondents who work under 10 years $(81.3 \%$ ). Based on the status of participation in patient safety training was 120 respondents $(80 \%)$ had attended training and 30 respondents $(20 \%)$ had never been participated in patient safety training.

Based on objective criteria, the level frequency distribution of dimension of social capital and the application of patient safety at Morowali Hospital can be known based on mean value (average). In the variable of structural dimension mean value of 25,3 is obtained, which means that if it is $\geq 25,3$ then will be categorized as high, on the contrary $<25,3$ then it is categorized as low, variable of relational dimension and cognitive dimension mean value of 25,8 is obtained, which means that if it is $\geq 25,8$ then will be categorized as high, on the contrary $<25,8$ then it is categorized as low. Meanwhile for the variable of the application of patient safetythe mean value of 182 is obtained, which means that if it is $\geq 182$ then it is categorized as high, on the contrary if it is $<182$ then it will be categorized as low. The following below is the level frequency distribution of knowledge sharing and the application of patient safety at Morowali Hospital 2019.

Based on table 2, it is known that 106 respondents were at a high structural dimension (social interaction) level (70.7\%), variable relational dimention (trust) it is known that 84 respondents were at a high level (56\%) and 78 respondents were at a high cognitive dimension (shared vision) level (52\%). While respondents who were at the level of implementation of high patient safety were 102 respondents $(68 \%)$, while around 48 respondents were included in the low category $(32 \%)$.

Table 3 presents the correlations among the variables included in the statistical analysis. The correlation coefficient (r) shows that positive correlation can be found between the variables social interaction toward application of patient safety $(\mathrm{p}=0.002<0.05, \mathrm{r}=0.251)$ with a correlation strength of 0.251 which means in the moderate category with positive direction, so high levels of social interaction are associated with high levels of patient safety. Furthermore, there was an almost as strong positive correlation between the variables shared vision toward application of patient safety ( $\mathrm{p}=0.000<0.05, \mathrm{r}=0.325$ ) with a correlation strength of 0.325 which means in the moderate category with positive direction. Meaning, high level of shared vision amongst nurse is associated with a high level of patient safety. There no significant influence of the relational dimension (trust) on patient safety can be found ( $\mathrm{p}=0,102>$ $0.05)$.

\section{Discussion:-}

This study aims to investigate the effect of the dimensions of social capital by applying patient safety at Morowali hospital in 2019. In this study it can be seen that there is a significant effect of social interaction and nurse's shared vision on the application of patient safety at Morowali Hospital. The social capital dimension in this study is social interaction includes the attitude of nurses in interacting with each other; the condition of mutual trust between nurses in carrying out tasks; describing the goals or shared vision, giving the same meaning and understanding in the organization. However, no results were found that affected the confidence of nurses in the application of patient safety at Morowali General Hospital.

In a study conducted in Taiwan 2012 three dimensions of social capital affect the knowledge of nurses who can further improve patient safety. This means that trust does not directly affect patient safety, but can reduce real and intangible barriers between nurses, high trust is needed to allow nurses to discuss the problems they face, and thus they gain new knowledge. (Chang et al., 2012)

In contrast to Auer's 2014 study, a cross-sectional study conducted showed that increased trust also contributed to patient safety, and research showed that patient trust and safety were interrelated (Auer, Schwendimann, Koch, De Geest, \& Ausserhofer, 2014) 
Research Chang et al, (2012) states that the social capital dimension facilitates the exchange and combination of knowledge which in turn improves patient safety. Thus, the administrator responsible for managing patient safety must develop a strategy or create a mechanism to encourage the climate of social interaction between nurses.

Increased communication, cooperation between nurses is generated from social capital (Waisel, 2005). Social capital in health care organizations can also have an impact on patient safety (Hofmeyer \& Marck, 2008).

Research from Jafari (2018) claims that social capital can improve risk management practices such as reporting errors, specifying the cause of an accident and the right actions after the occurrence of errors, these things can minimize the incidence of patient safety at the hospital.

Putnam, (1994) states that social capital as a characteristic of social life that includes networks, norms, and beliefs that enable individuals to behave together effectively to achieve common goals. In line with that Fukuyama (1998) states social capital is a set of shared values and norms shared among members of a community group that allows for cooperation among them. Social capital is the values of kindness in the positive or individual reciprocal cooperation relationships that shape the personality and character of society in achieving the well-being of life.

\section{Limitation of the study}

This study had some potential limitations that may affect the results. Some respondent may have not expressed their true opinions in some areas due to fear of negative effect on their work. In addition, the results of the study cannot be generalized to all medical personnel, we should cautiously generalize results of this study to other hospitals in the country.

\section{Conclusions And Recommendation:-}

On the whole, the results of this study confirm that there is a positive correlation between social capital dimension (structural,relational,cognitiv) and application of patient safety at Morowali Regional Hospital, therefore, social capital is one of the factors associated with the improvement of patient safety.

In this respect, hospital managers and other decision makers who work in this field can attempt to improve patient safety by increasing dimensions of social capital in hospitals. We suggest more applied and interventional studies for better understanding about the organizational culture and the social capital dimension.

Table 1. Respondent Distribution based on Characteristics in RSUD Morowali in 2019

\begin{tabular}{|c|c|c|c|}
\hline \multicolumn{2}{|c|}{ Characteristics } & \multicolumn{2}{|c|}{ Frequency } \\
\hline & & $\mathrm{n}$ & $\%$ \\
\hline \multirow[t]{2}{*}{ Age } & $20-29$ years & 73 & 48.7 \\
\hline & $30-39$ years & 77 & 51.3 \\
\hline \multirow[t]{2}{*}{ Gender } & Man & 35 & 23.3 \\
\hline & Women & 115 & 76.7 \\
\hline \multirow[t]{3}{*}{ Education } & D3 & 117 & 78.0 \\
\hline & S1 & 14 & 9.3 \\
\hline & Ners & 19 & 12.7 \\
\hline \multirow[t]{2}{*}{ Working Period } & $<10$ years & 122 & 81.3 \\
\hline & $\geq 10$ years & 28 & 18.7 \\
\hline \multirow[t]{2}{*}{ Training } & Ever & 120 & 80.0 \\
\hline & Never & 30 & 20.0 \\
\hline
\end{tabular}

Table 2. Frequency Distribution of Social Capital Dimension Levels for Nurses and Patient Safety at RSUD Morowali in 2019

\begin{tabular}{|c|c|c|c|c|}
\hline \multirow{3}{*}{ Variabel } & \multicolumn{4}{|c|}{ Category } \\
\hline & \multicolumn{2}{|c|}{ High } & \multicolumn{2}{|c|}{ Low } \\
\hline & $\mathrm{n}$ & $\%$ & $\mathrm{n}$ & $\%$ \\
\hline Structural & 106 & 70,7 & 44 & 29,3 \\
\hline
\end{tabular}




\begin{tabular}{|c|c|c|c|c|}
\hline & & & & \\
\hline Relational & 84 & 56,0 & 66 & 44,0 \\
\hline Cognitiv & 78 & 52,0 & 72 & 48,0 \\
\hline Application of Patient Safety & 102 & 68,0 & 48 & 32,0 \\
\hline
\end{tabular}

Table 3. The Statistical Relationship Between Social Capital Dimension and Patient Safety At RSUD Morowali In 2019

\begin{tabular}{|l|l|l|l|}
\hline \multirow{2}{*}{ Social Capital Dimension } & \multicolumn{2}{|l|}{ Patient Safety } & \multirow{2}{*}{ Category } \\
\cline { 2 - 3 } & p value & r value & \\
\hline Structural & 0.002 & 0.251 & Medium, positive and significant \\
\hline Relational & 0.102 & 0.134 & No correlation \\
\hline Cognitive & 0.000 & 0.325 & Medium, positive and significant \\
\hline
\end{tabular}

\section{References:-}

1. Aiken, L. H., Sloane, D. M., Clarke, S., Poghosyan, L., Cho, E., You, L., ... Aungsuroch, Y. (2011). Importance of work environments on hospital outcomes in nine countries. International Journal for Quality in Health Care. 23(4), 357-364. https://doi.org/10.1093/intqhe/mzr022

2. Auer, C., Schwendimann, R., Koch, R., De Geest, S., \& Ausserhofer, D. (2014). How hospital leaders contribute to patient safety through the development of trust. Journal of Nursing Administration. 44 (1), 23-29. https://doi.org/10.1097/NNA.0000000000000017

3. Bolino, M. C., Turnley, W. H., \& Bloodgood, J. M. (2002). Citizenship behavior and the creation of social capital in organizations. Academy of Management Review. https://doi.org/10.5465/AMR.2002.7566023

4. Chang, C. W., Huang, H. C., Chiang, C. Y., Hsu, C. P., \& Chang, C. C. (2012). Social capital and knowledge sharing: Effects on patient safety. Journal of Advanced Nursing, 68(8), 1793-1803. https://doi.org/10.1111/j.1365-2648.2011.05871.x

5. Despins, L. A., Scott-Cawiezell, J., \& Rouder, J. N. (2010). Detection of patient risk by nurses: A theoretical framework. Journal of Advanced Nursing. 66(2):465-474. https://doi.org/10.1111/j.1365-2648.2009.05215.x

6. Dhamanti, I., Leggat, S. G., \& Barraclough, S. (2019). The Role of Governments in the Implementation of Patient Safety and Patient Safety Incident Reporting in Indonesia : A Qualitative Study. Healthcare. 7(2):64:1-8

7. Doh, S., \& Zolnik, E. (2011). Social capital and entrepreneurship: An exploratory analysis. African Journal of Business Management. https://doi.org/10.5897/AJBM11.095

8. Firth-Cozens, J. (2004). Organisational trust: The keystone to patient safety. Quality and Safety in Health Care. https://doi.org/10.1136/qshc.2003.007971

9. Fleming, M., \& Wentzell, N. (2008). Patient safety culture improvement tool: development and guidelines for use. Healthcare Quarterly (Toronto, Ont.).

10. Fukuyama, F. (1995). The Social Virtues and the Creation of Prosperity. In New York: Free Press,.

11. Green, T. R. G., \& Petre, M. (1996). Usability analysis of visual programming environments: A "cognitive dimensions" framework. Journal of Visual Languages and Computing. https://doi.org/10.1006/jvlc.1996.0009

12. Griffiths, P., Renz, A., Hughes, J., \& Rafferty, A. M. (2009). Impact of organisation and management factors on infection control in hospitals: a scoping review. Journal of Hospital Infection. 73(1):1-14 https://doi.org/10.1016/j.jhin.2009.05.003

13. Hofmeyer, A., \& Marck, P. B. (2008). Building social capital in healthcare organizations: Thinking ecologically for safer care. Nursing Outlook, 56(4), 145.e1-145.e9. https://doi.org/10.1016/j.outlook.2008.01.001

14. Institute of Medicine. (2004). Keeping Patients Safe: Transforming the Work Environment of Nurses.

15. Jafari, M., Pourtaleb, A., \& Khodayari-Zarnaq, R. (2018). The impact of social capital on clinical risk management in nursing: a survey in Iranian public educational hospitals. Nursing Open, 5(3), 285-291. https://doi.org/10.1002/nop2.141

16. Kemenkes RI. (2017). Profil Kesehatan Indonesia 2016. In Profil Kesehatan Provinsi Bali.

17. Kohn, L. L., Corrigan, J. J., \& Donaldson, M. M. (1999). To Err Is Human. Building a Safer Health System, Volume 6. In International Journal of Public Health. https://doi.org/10.17226/9728

18. Leana, C. R., \& Pil, F. K. (2006). Social Capital and Organizational Performance: Evidence from Urban Public Schools. Organization Science. 17(3):353-366 https://doi.org/10.1287/orsc.1060.0191

19. Looman, W. S. (2006). Development and testing of the social capital scale for families of children with special health care needs. Research in Nursing and Health. 29 (4): 325-336 https://doi.org/10.1002/nur.20148 
20. MacPhee, M., \& Scott, J. (2002). The role of social support networks for rural hospital nurses: Supporting and sustaining the rural nursing work force. Journal of Nursing Administration. 32 (5): 264-272 https://doi.org/10.1097/00005110-200205000-00006

21. Manser, T. (2009). Teamwork and patient safety in dynamic domains of healthcare: A review of the literature. Acta Anaesthesiologica Scandinavica. 53(2), 143-151 https://doi.org/10.1111/j.1399-6576.2008.01717.x

22. Meterko, M., Mohr, D. C., \& Young, G. J. (2004). Teamwork culture and patient satisfaction in hospitals. Medical Care. 42(5), 492-498. https://doi.org/10.1097/01.mlr.0000124389.58422.b2

23. Nursalam. (2011). Manajemen Keperawatan Aplikasi dalam Praktik Keperawatan Profesional Edisi 3. Salemba Medika. https://doi.org/10.1001/archinte.165.22.2659

24. Poortinga, W. (2006). Social capital: An individual or collective resource for health? Social Science \& Medicine, 62(2), 292-302. https://doi.org/10.1016/J.SOCSCIMED.2005.06.008

25. Putnam, H. (1994). Sense, Nonsense, and the Senses: An Inquiry into the Powers of the Human Mind. The Journal of Philosophy. https://doi.org/10.2307/2940978

26. Putnam, R. D. (2002). Bowling Together: The United State of America. The American Prospect.

27. Reason, J. (1995). Safety in the operating theatre - Part 2: Human error and organisational failure. Current Anaesthesia and Critical Care. https://doi.org/10.1016/S0953-7112(05)80010-9

28. Sammer, C. E., Lykens, K., Singh, K. P., Mains, D. A., \& Lackan, N. A. (2010). What is patient safety culture? A review of the literature. Journal of Nursing Scholarship. 42(2): 156-165 https://doi.org/10.1111/j.15475069.2009.01330.x

29. Sheingold, B. H., Hofmeyer, A., \& Woolcock, M. (2012). Measuring the nursing work environment: Can a social capital framework add value? World Medical and Health Policy, 4(1): 1-17. https://doi.org/10.1515/1948-4682.1212

30. Spence Laschinger, H. K., \& Leiter, M. P. (2006). The impact of nursing work environments on patient safety outcomes: The mediating role of burnout/engagement. Journal of Nursing Administration. 36(5), 259-267 https://doi.org/10.1097/00005110-200605000-00019

31. Tsai, W., \& Ghoshal, S. (1998). Social capital and value creation: The role of intrafirm networks. Academy of Management Journal. https://doi.org/10.2307/257085

32. Waisel, D. B. (2005). Developing social capital in the operating room: The use of population-based techniques. Anesthesiology. 103 (6), 1305-1310 https://doi.org/10.1097/00000542-200512000-00026

33. WHO. (2009). Global Health Risks. Who. https://doi.org/10.2471/BLT.09.070565 